\title{
Personality traits as drivers of social preferences: a mixed logit model application
}

\author{
Friederike Paetz ${ }^{1}$
}

Published online: 9 July 2020

(c) The Author(s) 2020

\begin{abstract}
Currently, social consumption constitutes a rapidly increasing trend with significant potential for companies; moreover, the characterization of social consumers is highly relevant. To date, sociodemographic variables have been widely studied but appear to be less appropriate to uniquely characterize social consumers. Psychographic variables are credited with the ability to overcome these problems, since recent studies maintain that consumers' personal values and lifestyles are predictors of social consumption. However, personal values and lifestyle represent only two categories of psychological variables. Personality is another variable further known to be an antecedent of personal values and lifestyle. In this study, we focus on the characterization of social consumers based on both their personalities and sociodemographic variables. We conduct an empirical discrete choice experiment and investigate consumers' personalities as a driver of consumer preferences for the fair trade (FT) label attribute. To operationalize consumers' personalities, we use the popular five-factor approach. For the determination of consumers' preferences, we estimate a mixed logit model including both unobserved preference heterogeneity and observed heterogeneity. Observed heterogeneity is captured by consumers' personalities and sociodemographic variables. We find that gender, academic degree, income and four personality traits are important drivers of consumers' social preferences. We determine the interaction effects between sociodemographic and personality variables and argue for the consideration of personality in the characterization of social consumers as the core source of social preferences. A subsequent simulation study provides further insight into marketing strategies derived from the personality-characterization of social consumers.
\end{abstract}

Keywords Discrete choice experiment $\cdot$ Heterogeneity $\cdot$ Social product preference . Consumer personality

JEL classification M31-C38

Friederike Paetz

friederike.paetz@tu-clausthal.de

1 Department of Management and Marketing, Institute of Management and Economics, Clausthal University of Technology, Julius-Albert-Str. 6, 38678 Clausthal-Zellerfeld, Germany 


\section{Introduction}

Currently, social consumption, which is a part of sustainable consumption, constitutes a rapidly increasing trend with great potential for companies as evidenced by an increasing number of academic studies concerning social consumption and the increased interest of marketing practitioners in this topic (e.g., Tully and Winer 2014; Andorfer and Liebe 2012). Companies may benefit from the trend of social consumption by explicitly targeting social consumers. This could be accomplished by, e.g., offering products that are augmented with social product features, e.g., Fair Trade labels, or by positioning a brand using communication strategies, e.g., ethical branding (Fan 2005). The benefits of these two strategies are different. On the one hand, companies may increase revenues from the introduction of social products: The majority of the literature on social consumption documents a higher willingness to pay (WTP) for products with social product features in comparison to products that are not augmented with social product attributes (Tully and Winer 2014). Hence, price premia can be realized that develop the necessary basis for increases in a company's monetary benefits. On the other hand, companies may benefit from offering social products through increased sales or even greater market potential. This increase results from companies' addressing social consumers that purchase a company's social products or even entering the product market because of its social positioning. These types of behaviors are well-documented by studies showing that consumers increasingly rely on social product attributes when making purchase decisions (e.g., Auger et al. 2010).

Obviously, the introduction of social products is not a panacea to increase companies' product sales and/or revenue per se. The product category has an enormous influence on consumer preferences for social product attributes. For example, while higher WTP for social product attributes are well-documented in purely hedonistic product categories such as coffee or chocolate (e.g., Hainmueller et al. 2015; Rousseau 2015), purely utilitarian goods such as technical goods, e.g., computer mice, are not accompanied by an increased WTP if social product features are introduced and may even result in a decreased WTP for the product (Haase et al. 2016). Therefore, investigating the benefits of social product attributes for products that incorporate both hedonistic and utilitarian features, e.g., fashion, is highly beneficial.

If a company decides to jump on the social bandwagon, identifying the characteristics of "social consumers" becomes crucial. Describing social consumers ensures a deeper understanding of the entire social market segment. In contrast to the exclusive accommodation of preference heterogeneity by only offering products with and without social product features, the profiling of segments enables access to segments and helps to derive effective marketing instrument specifications, e.g., communication decisions, to target different segments (Wedel and Kamakura 2000, p. 4). Obviously, this argument is stronger if companies enter a new market, e.g., start to target segments that were not considered before. In this case, companies are not able to use past consumer purchase data to target them because it is not clear what the targeted segment looks like. This holds because - as mentioned before - a company's decision to offer social products may increase the market potential. 
Several studies have investigated individual background variables to describe the "social consumer" or draw inferences regarding consumers' preference or willingness to pay (WTP) for social product attributes. For example, Paetz and Guhl (2018) provide an overview of studies addressing sociodemographic variables to characterize social consumers. Thus far, (socio-) demographic variables have been the main focus. However, the results are contradictory: While some studies found no influence of (socio-) demographic variables on consumers' purchase intention or WTP for a social product attribute (e.g., Cranfield et al. 2010), other researchers provided evidence that supported (socio-) demographic variables' influence on consumer WTP and consumers' preferences for social product attributes (cp. De Pelsmacker et al. 2005). However, even if the influence of (socio-) demographic variables is supported, the direction of the influence is contradictory across different studies. While some researchers have described sensitive consumers as female (e.g., Paetz and Guhl 2017) or young (e.g., De Pelsmacker et al. 2005), other studies found older (Carrigan et al. 2004) consumers to be more sensitive to social product attributes. At first glance, those ambivalences may be traced back to several determinants, e.g., varying focal product categories, varying cultural contexts, etc. However, even among fixed contexts, e.g., same product category, the influence of sociodemographic variables does not point to a single clear description of the social segment. For example, Rousseau (2015) and Poelmans and Rousseau (2016) both considered fair trade chocolate with samples from Belgium. While Rousseau (2015) reported a decreasing probability of older respondents being assigned to segments that attach high importance to the fair trade label, Poelmans and Rousseau (2016) found that increasing age contributes to the probability of being assigned to a segment that prefers fair trade chocolate. Obviously, the characterization of social consumers based on (socio-) demographic variables alone (here: age) leads to inconsistencies. De Pelsmacker et al. (2005, p. 366) claimed that "demographics alone are not sufficient to define and identify the ethical consumer". In addition, Devinney et al. (2006, p. 8) stated that social consumption "is not just the purview of wealthy, highly educated females. [...] Rather it is something more deeply embedded in the psyche of an individual". Hence, several researchers have called for an all-embracing consumer description based on the consideration of psychological consumer characteristics. Although we have to keep in mind that we cannot expect psychological variables for the characterization of social consumers to lead to the same directions of effects in every study per se, psychological variables enhance the description of social consumers and, therefore, contribute to the derivation of effective and profitable marketing strategies both on a strategic and operational basis as discussed before.

To classify psychological consumer characteristics, Wedel and Kamakura (2000), p. 11, differentiate among the following three categories: "lifestyle", "personal value" and "personality". Figure 1 shows these categories, illustrates the reported influences of psychological variables on sustainable consumption in the recent literature and displays further relationships among the three categories of psychological variables (see solid arrows). Obviously, many other relationships exist, e.g., between cultural variables and sociodemographic variables, such as income (e.g., World Data 2019), or between sociodemographic and psychographic variables (e.g., Costa et al. 2001). However, we did not provide a formal image of these relationships in Fig. 1 to 




Fig. 1 Individual background variables influencing sustainable consumption

enhance clarity and because we aim to highlight the focal research topic of this contribution, i.e., the determination of personality's influence on social consumption.

Apparently, all categories of psychological consumer characteristics may potentially affect consumers' preferences for sustainable consumption. To capture the psychological influence of consumers' personal values, such as family security or wisdom, on social consumption, several studies have been conducted (e.g., Dickson 2000; Fritzsche 1995; Anderson and Cunningham 1972), and better characterizations of the social consumer have been developed. For example, based on these results, De Pelsmacker et al. (2005) investigated the influence of consumers' personal values (as measured by the Rokeach Value Survey) on ethical purchase behavior and described social consumers as more idealistic and less conventional. Balderjahn and Hüttel (2019) scrutinized the impact of personal values (as measured by Schwartz's Portraits Values Questionnaire) on consumers' consciousness-for-sustainable-consumption (CSC) and further determined CSC's impact on sustainable consumption. These authors found that the personal value "universalism" positively influences (all three dimensions of) CSC, which positively affects consumers' sustainable purchase behavior.

Currently, in the context of sustainable consumption, consumer lifestyle is frequently studied. For example, studies have increasingly focused on a specific (lifestyle-based) consumer segment called LOHAS (Lifestyle of Health and Sustainability) (e.g., Ray and Anderson 2000; Wenzel et al. 2007). LOHAS consumers are described as consumers who live a sustainable lifestyle and prefer sustainable (and therefore social) products (cp. Helmke et al. 2016, pp. 4). This consumer segment is highly relevant for marketing managers because the market potential is already large and still increasing worldwide (cp. Schüpbach et al. 2007 , p. 28). Although numerous studies have addressed LOHAS consumers and explained their characteristics, a concrete derivation of the sociodemographic composition of this segment is lacking. One exception is the study conducted by Glöckner et al. (2010), who attempted to characterize the LOHAS segment by using the Sinus-Milieu concept to simplify the derivation of the LOHAS' sociodemographic characteristics and, therefore, the derivation of managerial 
implications. However, detailed research primarily investigating the influence of consumer lifestyle on consumer WTP for social product attributes is sparse (cp. Schüpbach et al. 2007).

In contrast to the number of studies linking consumers' personal values or lifestyles and sustainable consumption, research explicitly linking the (individual) personality of consumers to their preference for social product attributes is sparse (see dashed line in Fig. 1). In particular, research investigating the role of consumers' personality traits in social consumption (as a part of sustainable consumption) using an all-encompassing approach is lacking. However, research in this field seems to be highly interesting. The examination of consumer personality's influence on purchase preferences helps to describe social consumers in more detail and, to some degree, provides an inverse connection to popular upto-date studies in the context of digital advertising that draw personality information from product preferences measured via Facebook likes or Tweets (e.g., Matz et al. 2017; Clark and Calli 2014).

Personality is (obviously) inherent in all consumers and known as an antecedent of personal values and lifestyle (e.g., Divine and Lepisto 2005; Rokeach 1973) as displayed in Fig. 1. In contrast to personal values and lifestyle, personality is known to be stable over time (cp. Costa and McCrae 2003; McCrae et al. 2000). Hence, the profiling of social consumers with personality variables leads to time-stable results that remain unaffected by global social trends. Therefore, research concerning the link between consumers' personality and their preference for social product attributes provides a sound/solid basis for the long-term strategic marketing decisions of companies' marketing managers and the robust profiling of social consumers, which is crucial for marketing scholars and sociologists.

To contribute to the sparse literature in the mentioned research field, we conduct an empirical discrete choice experiment in the denim jeans category and investigate whether consumer personality, e.g., specific personality traits, is a driver of consumers' preference for the Fair Trade (FT) label attribute (as a surrogate for social consumption). Therefore, we estimate a mixed logit (MXL) model that incorporates several interactions terms, e.g., consumers' personality traits, age, gender, size of household, academic graduation and monthly household income. Furthermore, we perform a simulation study and show how marketing managers could use the personality characterization of social consumers to derive successful marketing strategies.

The remainder of this paper is organized as follows: In Sect. 2, we provide the theoretical foundation and introduce the concepts of consumer personality, lifestyle and personal value. In addition, we analyze the relationships among these concepts. Furthermore, we provide information regarding the MXL model, which is used for the data estimation. In Sect. 3, we present the data and results of our empirical study. Subsequently, we present a small simulation study used to derive the managerial implications. We conclude our study in Sect. 4 and discuss the limitations and future research issues. 


\section{Theoretical background}

In the following section, we provide the theoretical background by briefly reviewing the constructs of consumer personality, lifestyle and consumer personal values in Sect. 2.1. In Sect. 2.2, we subsequently review the selected literature highlighting the relations and differences between personality and personal value to explicitly display our research contribution and novelty based on an investigation of personality drivers of social product preferences. In Sect. 2.3, we derivate relationships between the personality traits of consumers and their preference for a social product attribute and formulate the hypotheses. In Sect. 2.4, we provide information regarding a new MXL model, which is used for the estimation of consumer preferences.

\subsection{Definitions and differentiations of personality, personal values and lifestyle}

We follow the definition provided by McCrae and Costa (1996) and McCrae and Costa (2008, p. 165) and view human personality as a description of individuals in terms of thoughts, feelings and behavior. Personality has a biological/genetic foundation, and therefore, "personality traits are endogenous basic tendencies that (could only) be altered by exogenous interventions, processes, or events that affect their biological bases" (e.g., a brain tumor) (McCrae and Costa 2008, p. 165). Several studies have empirically proven the validity of this definition and argue that personality is relatively stable throughout adulthood (e.g., Harris et al. 2016; McCrae and Costa 1982).

Following the popular five-factor theory, human personality is formed by the following five distinct personality traits: extraversion, neuroticism, openness to experience, agreeableness, and conscientiousness. Extravert personalities have social skills and are described by facets, such as warmth and assertiveness. Neurotic persons are anxious, tend to suffer from depression and have pessimistic attitudes. Open personalities are interested in travel and tend to prefer fantasy. Agreeable personalities believe in cooperation and exhibit altruistic behavior, while conscious personalities are dutiful and show leadership skills (cp. McCrae and Costa 2008, p. 164; McCrae and Costa 1996, p. 67).

This five-factor model has become the leading tool used to operationalize personality because several studies have proven the five factors of personality to be invariant to the considered culture and age (in adulthood), rendering this model powerful and robust (e.g., McCrae and Costa 2013; Specht et al. 2011; McCrae et al. 2005).

To determine the personality of an individual, several personality tests exist. These tests primarily rely on rating scales in which the respondents evaluate themselves with regard to different facets (e.g., Gosling et al. 2003; Costa and McCrae 1992; Goldberg 1992). Commonly, the results of different facets are pooled to achieve the results of the associated factor. For example, to assess a consumer's extraversion level, the results of that consumer's self-assessment of facets, including warmth, gregariousness and assertiveness, are aggregated.

In contrast to inborn (biological) personality traits, personal values are commonly described as the product of a person's environment and reflect a person's motivation 
(Parks-Leduc et al. 2015, p. 5). Personal values are personal temporal life goals that guide a person's behavior (Parks-Leduc et al. 2015, p. 3). To assess personal values, several approaches exist. In the psychological literature, the circle value model proposed by Schwartz (1992), which includes different value types, such as tradition, power, and hedonism, is very popular. In the marketing literature, the Rokeach Value Survey (RVS) in which respondents are asked to rank several personal goals, such as freedom, family security, and self-respect (Asendorpf 2004, p. 240), and the List of Values concept proposed by Kahle (1983), which is based on the personal goals used in the RVS (Kahle et al. 1986, p. 206), are often used to operationalize personal values.

The concept of lifestyle was first introduced in the marketing literature by Lazer (1963). The term "lifestyle" describes how people spend their time, how they live, how they recognize other individuals and their main interests (Kucukemiroglu 1999). To assess the lifestyle of individuals, the AIO-approach proposed by Wells and Tigert (1977) is highly popular. In this approach, individuals evaluate several statements about their activities (A), interests (I) and opinions (O). However, the AIO-approach is frequently criticized due to the lack of replicability, which stems from less time-stable attitudes (e.g., Newton and Meyer 2013).

In contrast to personality traits, personal values and lifestyle are influenced by exogenous factors. For example, culture has a strong impact on personal values and lifestyle (Lee and Sparks 2007; Inglehart and Beker 2000). Therefore, studies considering the impacts of personal values on other concepts, such as consumer preference for social product attributes, are culture-dependent, and the generality of the results is limited. In contrast, the investigation of personality traits overcomes this problem and leads to an all-encompassing view of the psychological determinants of social consumption.

\subsection{Literature review}

In the psychological literature, there has been a great debate regarding the similarities and differences between human personality and personal values. While some researchers view personality and personal values as completely interchangeable constructs, other scholars distinguish between these constructs (in varying degrees of overlap, i.e., completely different versus related to some extent). A meta-study conducted by Parks-Leduc et al. (2015) found that differences actually exist between personality and personal values, and therefore, the authors strongly contributed to a deeper understanding of the relevant research field. Although differences are present between these constructs, personality and personal values are related to some extent. In this context, some personality factors are more closely related to personal values than other factors. For example, Fischer and Boer (2015) found that the personality traits agreeableness and openness to experience have the strongest association with personal values. Rokeach (1973) argued that a person's personality is an antecedent of the person's personal value. Hence, the investigation of personality as a driver of consumers' preference for a social product attribute implicitly also encompasses investigating the potential of personal values to act as drivers. 
As previously mentioned, research linking consumer preferences for social product attributes to consumer personality is sparse. One additional exception is the study conducted by Grankvist and Kajonius (2015), who investigated the predictive potential of personality and personal values for consumers' WTP (and, therefore, consumers' preferences) for social product alternatives. However, the primary goal of this study was to identify differences in the psychological constructs of personality and personal values, and, therefore, this study focuses on the psychological context rather than the marketing context. Hence, the results are tailored to differences between these two psychological constructs rather than econometric or managerial implications for marketing managers regarding social product enhancements. In particular, Grankvist and Kajonius (2015) replicated the popular study conducted by Roccas et al. (2002), who investigated the predictive potential of personality and personal values for religiosity and positive affect. On the one hand, Roccas et al. (2002) determined that "values, as cognitive representations of motivations in the form of goals and objectives [have stronger influence on behaviors] over which individuals have cognitive control or choice" (p. 793). On the other hand, traits have a stronger influence on behavior with minimal cognitive control and are "better predictors of spontaneous, intuitive and emotionally driven attitudes and behaviors" (p. 793). In an FT context, Grankvist and Kajonius (2015) asked the respondents to directly state their WTP for FT alternatives and found that personal values and personality traits correlate with consumer WTP. Although these scholars determined that personal values account for more variance in consumer WTP than personality traits in their study, they referred to Rokeach (1973) and conceded that personal values are actually influenced by personality traits. In particular, two personality factors, e.g., openness and agreeableness, had a considerable overlap with personal values.

Although the general research questions regarding the psychological drivers of consumers' preference for social products in our study and the study conducted by Grankvist and Kajonius (2015) seem similar, there are several differences.

In contrast to Grankvist and Kajonius (2015), we (1) investigate consumers' preference for an FT label attribute by using a discrete choice experiment. As a social product attribute, the FT label is highly relevant in this context. Recent research has shown that (worldwide) the number of people who attach high importance to the FT label when making a purchase decision is high and still increases (Statist 2019). Furthermore, discrete choice experiments represent an indirect method to determine consumers' preferences. The estimation results obtained using indirect measurement methods are known to suffer less from highly inflated estimates because the socialdesirability-bias is less prevalent compared to that using the direct methods used by Grankvist and Kajonius (2015) and Roccas et al. (2002). (2) While Grankvist and Kajonius (2015) used the FT products roses, bananas, footballs and cups of coffee, we use the product category of denim jeans. Jeans constitute fashion products, and hence, choices between denim jeans are known to be more emotionally driven than choices between nondurable goods, such as food and flowers (cp. Watson and Yan 2013). Considering the results reported by Roccas et al. (2002), who found that personality traits predict behaviors even better if they are emotionally driven, we may expect personality traits to have a greater influence on denim jeans purchases in general than fast-moving consumer-goods purchases, such as bananas, etc. In addition, 
denim jeans are highly underrepresented in relevant studies as revealed by a metaanalysis conducted by Tully and Winer (2014) in which no single study among a list of more than 80 studies concerning sustainable consumption considers denim jeans. However, denim jeans represent a frequently purchased product and are widely spread across consumers of varying genders, ages, social classes, etc. in Germany. (3) Hence, our results could be used for interstudy comparison with Grankvist and Kajonius (2015), and we could examine the results reported by Roccas et al. (2002) based on the exploratory power of personality traits for consumers' preference of social attributes of a more emotional product category (denim jeans versus coffee in the study by Grankvist and Kajonius (2015)). (4) While Grankvist and Kajonius (2015) and Roccas et al. (2002) used student samples, we use a representative German sample. Student samples are obviously biased by young and highly educated respondents and, therefore, lead to less generalizable results. The use of a representative sample may further contribute to generalizing the findings of previous studies if parallels become obvious. (5) We directly apply our results in a marketing context. The main purpose is to draw inferences for marketing managers in the field of social consumption. For example, we enable managers to make decisions regarding investment in social product enhancements and the advantageousness of consumer segmentation to increase companies' profits. We are interested in the psychological characterization of social consumers rather than the pure distinction between consumers' personality and personal values and the determination of potential personality drivers of social consumption. In contrast to time-varying personal values, timestable personality traits are highly relevant for long-term marketing decisions.

In this context, we have to keep in mind that "long-term" marketing decisions do not coincide with marketing decisions that are fixed over decades/generations, but with strategic marketing decisions. Strategic marketing decisions last, on average, for three to five years (Aaker 2008). The characterization of consumers enables marketing managers to establish policy tools for different market segments that at best result in increasing customer satisfaction and revenue (Abou-Zeid and Ben-Akiva 2014, p. 407).

These issues clearly differentiate our study from the study conducted by Grankvist and Kajonius (2015) and the recent literature and show the novelty and contribution of our study to the relevant marketing literature.

In addition, our paper adds contributions from a methodological point of view. While several studies have incorporated sociodemographic variables as observed heterogeneity into a MXL model (e.g., Rasouli and Timmermans 2016; Greene et al. 2006; Warburg et al. 2006; Bhat and Gossen 2004), the consideration of psychographic variables is sparse. In particular, the consideration of personality variables in MXL models is less researched. To the best of our knowledge, no study has incorporated personality measured by the five factor model as an explanatory variable in a MXL model. Paetz (2016) used personality variables measured by the five factor model to show that personality actually influences consumer preferences. The author uses separate steps to determine segment-specific preferences, e.g., profiling of latent class MNL models with personality and clustering of individual preferences resulting from choice-based conjoint hierarchical Bayes estimates by personality traits. In contrast, our MXL model estimates individual preferences by 
simultaneously accounting for personality variables. Hence, we are the first to incorporate personality — measured by the five factor model—as observed heterogeneity in a MXL model and, therefore, estimate the influence of personality on individual preferences simultaneously.

\subsection{Hypotheses}

We formulate hypotheses regarding the expected personality traits' influence directions on consumers' preferences for social product attributes.

Extraversion: Extravert personalities are inter alia described as sociable and social but also as vain and conceited (Goldberg 1990). The FT label considers people, e.g., workers or commodity producers, beneficiaries, corresponding to the social facets of extraversion. In this context, De Raad (2000) determined that extravert persons tend to seize social jobs. However, even other attributes that target vanity could be linked to the FT context. FT products are associated with a higher quality (Renard 2003). Hence, vain or conceited persons tend to choose FT products to differentiate from other people, who buy conventionally traded products. Hence, all these facets suggest the following:

H1 Consumers who score high on the factor extraversion show an increased preference for the presence of an FT label.

Neuroticism: Neurotic persons have nervous tensions and feel guilt (McCrae and Costa 1987). These individuals are emotionally unstable and oversensitive (Goldberg 1990). Based on the results of a recent study conducted by Peloza et al. (2013), who found that the desire to avoid anticipated guilt is a driver of consumers' preference for ethical (and, therefore, social) products, we expect a positive relationship to exist between neuroticism and social product preferences. Furthermore, people who exhibit a high neuroticism score are known to have a tendency for social comparison, e.g., passive use of Facebook (Rozgonjuk et al. 2019). Hence, it seems intuitive that neurotic personalities seek general orientation through other persons or organizations. The FLO (Fair Trade Labelling Organization) may operate as such a leader. The FT label conveys safety and security (FairTrade 2018), which should positively affect neurotic persons.

H2 Neuroticism exerts a positive effect on consumers' preference for the FT label.

Agreeableness: This personality trait "involves the more humane aspects of humanity" (Digman 1990, p. 422). Agreeable personalities engage in altruistic and caring behavior (Digman 1990, pp. 422-424). Thus, the FT label ensures compliance with the rights of workers and, therefore, corresponds to the facets assigned to the factor agreeableness.

H3 Agreeableness exerts a positive effect on consumers' preference for the FT label. 
Consciousness: Along with the factor agreeableness, consciousness is perceived as a factor with "moral overtones" (McCrae and John 1992, p. 197). Conscious persons are orderly and set and obey moral standards (Cranford and Smith 1987). The FT label matches in this context because it testifies compliance with moral/social standards. Hence, the preference for the FT label and the factor consciousness should be positively related as follows:

H4 Consciousness has a positive effect on consumers' preference for the FT label.

Openness: The factor Openness is related not only to facets, such as openness to feelings and new ideas (Digman 1990, p. 424), but also cultural interest and educational aptitude (Hogan 1986). The FT label symbolizes these facets because commonly, the FT label is relevant for famers, etc. from different cultures from the Global South, e.g., poor or emerging countries. In particular, the educational aptitude of highly open people may strengthen their preference for social product enhancement. The purchase of social products places customers in the role of an ideal, which they may use to educate others regarding social consumption.

H5 Openness exerts a positive effect on consumers' preference for the FT label.

Initially, these hypotheses seem weird or even senseless because all personality traits result in the same positive direction of consumer social preferences. However, we must consider that the personality of a consumer is determined by all five personality traits simultaneously. Different personality types, e.g., varying compositions of personality trait levels, could actually yield the same social preferences. For example, we could contrast the social preferences of different personality types, e.g., a consumer's personality may comprise high levels of extraversion and neuroticism and low levels of agreeability, openness and consciousness, while another consumer may scale low in extraversion and neuroticism and high in agreeability, openness and consciousness. However, even different personality types may actually yield the same total preference for social products. This possibility is highly interesting from a marketing perspective because it provides important information regarding the targeting of markets, e.g., market segmentation.

\subsection{Mixed logit model}

To determine the respondents' preferences for social product attributes, we use a discrete choice analysis (e.g., Rao 2014). Here, it is assumed that a choice alternative could be considered a bundle of $K$ (prespecified) attributes, $k=1, \ldots, K$, with $\mathrm{L}_{\mathrm{k}}$ levels, respectively. In a discrete choice experiment, the respondents evaluate a fixed number $J$ of different alternatives in several choice sets $T$. In the evaluation of the results, it is assumed that the respondents choose the alternative that provides the greatest (stochastic) utility in a certain choice set $t, t=1, \ldots, T$. We rely on random utility theory, which assumes that the (stochastic) utility of a certain alternative $j$ for 
respondent $i$ in choice set $t$ is decomposed into a deterministic utility component and a random error term as follows:

$$
u_{j t i}=x_{j t i}^{\prime} \cdot \beta_{i}+\varepsilon_{j t i}
$$

The deterministic part constitutes the part-worth utilities $\beta_{i}$ of all (prespecified) attributes (levels) multiplied by the transposed vector of the related attribute levels. If dummy coding for all nonprice attributes and a linear price parameter as well as the accommodation of a 'no-choice' parameter is considered, the part-worth parameter vector $\beta_{j}$ is of length $\left(\sum_{k=1}^{K-1}\left(L_{k}-1\right)\right)+1+1$. In this case, the vector $x_{j t i}$ contains dummy-coding for all nonprice attributes as well as the price level of alternative $j$ in choice set $t$ evaluated by respondent $i$ and a no-choice parameter. Therefore, $x_{j t i}$ has the same length as $\beta_{i}$. All determinants of the (stochastic) utility that are not incorporated in the deterministic part of the utility are agglomerated in the random error term $\varepsilon_{j t i}$. If the random error term is assumed to be Gumbel distributed, the choice probability $p r_{j^{*} t i}$ of alternative $j^{*}$ is closed-form as follows:

$$
p r_{j^{*} t i}=\frac{\exp \left(x_{j^{*} t i}^{\prime} \cdot \beta_{i}\right)}{\sum_{j=1}^{J} \exp \left(x_{j t i}^{\prime} \cdot \beta_{i}\right)}
$$

where $J$ denotes the (fixed) length of the choice sets.

If we assume that all respondents behave in the same manner, we estimate an aggregated Multinomial Logit (MNL) model and determine aggregated part-worth utilities. Hence, we do not consider unobserved heterogeneity by estimating individual/random parameters or observed heterogeneity by considering that observed variables such as sociodemographics or psychographics may influence respondent's preferences.

The accommodation of unobserved heterogeneity or even both types of heterogeneity, i.e., observed and unobserved heterogeneity, is ensured within the MXL model. The MXL model's random parameters can be given via the following equation (Allenby and Ginter 1995):

$$
\beta_{i}=\Gamma \cdot z_{i}+v_{i}, v_{i} \sim \operatorname{MVN}(0, \Omega)
$$

The respondent's unobserved heterogeneity is modeled via the random term $v_{i}$, which is assumed to be $\left(\sum_{k=1}^{K-1}\left(L_{k}-1\right)\right)+1+1$-variate Gaussian distributed with a zero mean and covariance matrix $\Omega$. Observed heterogeneity is captured by the vector $z_{i}$, which contains respondent-specific observed variables, such as sociodemographics and psychographics. Its length equals the number of observed variables, $H$. The effects of those observed respondent-specific variables on the respondents' partworth utilities are included in the matrix $\Gamma$, which is of the format $\left(\sum_{k=1}^{K-1}\left(L_{k}-1\right)\right)+1+1 \times \mathrm{H}$. Obviously, the elimination of the first summand of representation (3) degenerates the MXL model into an MXL model that accounts for unobserved heterogeneity only. Although, psychographics are captured as observable heterogeneity, they are not directly observable, similar to demographics, and 
have to be measured by a personality test (Wedel and Kamakura 2000, p. 7). AbouZeid and Ben-Akiva (2014) call these indicators (here: personality test) of the latent variable (here: personality) and illustrate their relationships to the overall utility. As the authors illustrate, it is likely that measurement errors from the personality test influence the results of the MXL model that incorporates psychographics (through a structural equation model) as explanatory variables, i.e., observed heterogeneity. It is likely that measurement errors lead to an attenuation bias in the estimated effects of the personality traits on preferences. That has to be kept in mind for the final interpretation of the results by - for example - the consideration of a lower significance level. $^{1}$

The estimation of the part-worth utilities could be performed by maximum (simulated) likelihood estimation (McFadden and Train 2000). If we presume independence across the alternatives and respondents, the log-likelihood function is as follows:

$$
L L(\Gamma, \Omega)=\sum_{i=1}^{I} \ln \left(\int \prod_{t=1}^{T} \prod_{j=1}^{J}\left(p r_{j t i}\right)^{\delta_{j t i}} \cdot \phi(\nu \mid 0, \Omega) d \nu\right)
$$

where $\delta_{j t i}$ is a dummy-variable that equals 1 if respondent $i$ choses alternative $j$ in choice set $t$ and zero otherwise. $\phi(\nu \mid 0, \Omega)$ is the density function of all parameters conditional on the zero mean and covariance matrix $\Omega$ of the multivariate Gaussian distribution in formula (3) (Elshiewy et al. 2017, p. 41). Obviously, while the MNL model's choice probability is of closed form, the MXL model inhibits no closedform choice probability and the MXL model's log-likelihood function contains a multidimensional integral. To simplify the evaluation, Monte Carlo simulation, which approximates the integral through to several draws based on the relevant distribution, is highly prominent (Train 2009). A detailed explanation on varying estimation approaches for the MXL model is discussed by Elshiewy et al. (2017).

\section{Empirical study}

In the following section, we present the data of our empirical study in Sect. 3.1 and discuss the results in Sect. 3.2. Section 3.3 describes a small simulation study performed to draw managerial inferences from the previously received results.

\subsection{Data}

We conducted an empirical study using the product category of denim jeans in winter 2017/2018. We distributed our questionnaire via an online survey to a representative German sample. The respondents who stated that they buy jeans (our focal product) in general completed the questionnaire, which consisted of three parts. The

\footnotetext{
${ }_{1}^{1}$ Thank you very much to an anonymous reviewer for pointing this out!.
} 
first part included sociodemographic questions, e.g., the respondents' age, gender and income. The second part included a personality self-test, which was adopted from Saum-Aldehoff (2012), pp. 190-198. The German personality test by SaumAldehoff (2012) is based on the markers for the big-five factor structure of Goldberg (1992) and uses 50 items to describe the five personality traits, e.g., 10 items per personality trait. Using 5-point uni-polar rating scales, each respondent states how -for example- talkative, reserved or shy she/he is. The results of those facets are aggregated to achieve a final score for each factor. The factors' scores range between -20 and +20 . For example, if a consumer's extraversion factor is $\mp 12$, the consumer likely has an introvert/extravert personality. The Saum-Aldehoff (2012) test is relatively short and provides a first diagnosis of personality (Saum-Aldehoff 2012, p. 190). Therefore, measurement error in our MXL model that integrates a structural equation model for personality is likely to be prevalent.

The third part was based on a choice task. The choice task consisted of 16 choice sets with a dual-response design. Hence, each respondent faced two questions for each choice occasion. First, each respondent had to choose her or his favorite jeans from four jeans alternatives. Second, each respondent was asked whether she or he would truly buy the previously selected jeans alternative in a current marketplace (cp. Diener et al. 2006, p. 157).

The jeans alternatives were described using the following attributes: brand (Diesel, G-Star, Levi's, or Replay), price $(50 €, 90 €, 130 €$, or $170 €)$, design (traditional, trendy) and the inclusion of an FT label (no, yes). The first attribute level serves as the reference category. The attributes (and attribute levels of the design attribute) were chosen in accordance to recent discrete choice experiments in the product category of jeans frequently reported in the literature (e.g., see literature overview by Jin et al. 2010). The considered brands are the most preferred manufacturer denim jeans brands in Germany across gender and age classes (Statista 2015). The price levels were selected as relevant price levels for denim jeans (of regular length) of the considered brands at a famous German online retailer.

In total, 353 respondents completed the survey. We excluded the respondents who selected the same jeans alternative in more than 12 choice sets $(=75 \%)$, e.g., always the jeans shown as the second alternative in the first question, or selected the nobuy alternative in the second question. The exclusion of these respondents was performed because such a straight-lining behavior suggests that such respondents did not take the choice task seriously. Hence, biased results could arise if we included the straight-liners in our data base.

The final sample included 293 respondents and closely represents the sociodemographic distribution in Germany. Since (almost) every person in Germany owns jeans (Jeansdirect 2018), we can use the whole German population as a benchmark. Table 1 provides a comparison of the sociodemographic distribution in our sample compared to the distribution in Germany in 2018:

Approimatley $50 \%$ of the respondents were female, and the mean age was approximately 44 years. In the sample, approximately $62 \%$ of the respondents had a monthly (household) income lower than $2600 €$, approximately $94 \%$ of the respondents lived in a household with a maximum of four persons, and approximately $17 \%$ of the respondents held an academic degree. 
Table 1 Sociodemographic distribution (Statista 2018a, b, c, d, e)

\begin{tabular}{lll}
\hline & Germany & Sample \\
\hline Mean age & 44.40 years & 43.54 years \\
Female & $50.65 \%$ & $49.49 \%$ \\
Monthly (household) income $<2600 €$ & $56.81 \%$ & $62.12 \%$ \\
Academic degree & $18.00 \%$ & $17.41 \%$ \\
Size of household $<5$ persons & $96.64 \%$ & $93.86 \%$ \\
\hline
\end{tabular}

Table 2 Correlations among the individual background variables

\begin{tabular}{lrrrrrrrrr}
\hline & $\mathrm{O}$ & $\mathrm{E}$ & $\mathrm{C}$ & $\mathrm{N}$ & $\mathrm{A}$ & Age & Female & Acad. & Income \\
\hline $\mathrm{E}$ & 0.251 & & & & & & & & \\
$\mathrm{C}$ & 0.354 & 0.360 & & & & & & & \\
$\mathrm{~N}$ & -0.116 & -0.277 & -0.265 & & & & & & \\
$\mathrm{~A}$ & 0.305 & 0.314 & 0.448 & -0.261 & & & & & \\
Age & 0.130 & 0.077 & 0.108 & -0.216 & 0.069 & & & & \\
Female & 0.247 & 0.133 & 0.197 & 0.010 & 0.304 & 0.076 & & & \\
Acad. & 0.250 & -0.088 & -0.022 & -0.037 & -0.085 & 0.119 & 0.060 & & \\
Income & 0.095 & 0.155 & 0.123 & -0.147 & 0.046 & 0.093 & 0.110 & 0.190 & \\
hh-size & 0.115 & -0.023 & 0.054 & 0.140 & 0.074 & -0.279 & 0.100 & -0.120 & 0.240 \\
\hline & & & & & & & & &
\end{tabular}

The mean values of the personality vectors yield a highly agreeable (10.860), highly conscious (10.038), extravert (3.502), open (5.676) and less neurotic $(-2.608)$ personality structure. These personality results coincide with those of other studies examining the German personality structure (e.g., Schön 2007). We conduct an exploratory factor analysis of the personality traits. The overall Kaiser-Meyer-Olkin index is 0.868 , indicating that the sample-data correlation matrix is appropriate for the factor analysis. The five-factor solution yields high factor loadings (approximately 0.6 for extraversion, agreeableness, consciousness, and openness, approximately 0.5 for neuroticism) and a large average extracted variance (0.470). In addition, we observe high reliability as indicated by the internal consistency criteria; that is, Cronbach's $\alpha$ is 0.746 (Streiner 2003).

Table 2 displays the correlations among our focal individual background variables. We obtained two different types of individual background variables, e.g., continuous and discrete/categorical variables, and, therefore, three types of correlations. (1) Between any two continuous variables, we could simply calculate the Pearson's correlation coefficient (compare columns 2 and 7 on lines 2 to 6). All personality variables interact, but the correlations are rather small. Neuroticism is the only personality trait that is negatively correlated with all other personality traits as follows: an increasing level of neuroticism leads to decreasing levels of all other personality traits and vice versa. The correlations between age and the personality traits are quite small if they differ from zero at all. This finding argues for the time-stableness of the personality traits, which was already previously discussed (see Sect. 1). (2) Between the continuous variables and binary variables (compare columns 2 and 7 
on lines 7 to 10), we calculate the point-biserial correlation. Women yield higher values in all personality traits. The same applies to the higher income class; a higher income corresponds to higher values in all personality traits, except for neuroticism, which is lower. For example, consumers with a monthly household income higher than $2600 €$ are more extraverted (4.523 versus 2.879 ) but less neurotic ( -3.360 versus -2.148 ) than their corresponding counterparts. People with an academic degree are more open (8.255 versus 5.132) than those without an academic degree. Hence, the sociodemographic drivers of consumers' preference for social product attributes may be traced to the consumers' personality traits. (3) Between the binary variables (compare columns 7 and 10 on lines 7 to 10), we assume bivariate normality and calculate the tetrachoric correlation (Günther and Höfler 2006). The directions of the correlations seem plausible; a higher household income corresponds to more household members or an academic degree.

Although many variables are indeed correlated, the degree of correlation is low or moderate. In summary, we observed that there is no issue with multicollinearity, providing a sound basis for the estimation of the MXL model.

\subsection{Results}

For the estimation, we used 14 choice sets and considered two holdouts. The consideration of two holdouts (relative to cross-validation methods) is appropriate here because we have enough data for the estimation (293 respondents times 14 choice sets $=4102$ observations). Based on 14 choice sets, the general shares of the (hypothetical) alternatives in the choice sets are $20.88 \%, 21.75 \%, 21.52 \%$ and $20.39 \%$. Obviously, the choice shares are on par, arguing for an equally well balanced choice design (Huber and Zwerina 1996). Furthermore, the choice share of the 'no-buy' option at $15.25 \%$ is rather small, ${ }^{2}$ further highlighting the quality of the choice design/data and providing a sound basis for our estimation. Based on the data, we estimated MXL models with the mlogit-package of the free software $\mathrm{R}$ and used 1000 draws within the Monte Carlo Simulation (Croissant 2020). We considered the following four types of MXL models and used the aggregated MNL model as a benchmark. Here, only seven parameters, that is, (aggregated) part-worth utility parameters, are estimated. The MXL0 model accounts for unobserved heterogeneity only and, hence, does not consider observed heterogeneity through the respondent-specific variables. Here, seven average part-worth utility parameters and 28 covariance parameters are estimated for 35 total parameters. The MXL1 resp. the MXL2 model accommodates the observed heterogeneity by incorporating the sociodemographic variables, i.e., age, gender, monthly household income, size of household and education, e.g., whether the respondent holds an academic degree, resp. personality traits, e.g., extraversion, neuroticism, agreeableness, conscientiousness and openness to experience. Here, seven average part-worth utility

\footnotetext{
${ }^{2}$ We did not consider the choice of alternatives in the first question in our calculation of the choice shares if the respondent chose the 'no-buy' option in the second question.
} 
Table 3 Model statistics

\begin{tabular}{llllll}
\hline & MNL & MXL0 & MXL1 & MXL2 & MXL+ \\
\hline Obs. het. & No & No & Sociodem. & Personality & Sociodem. + Personality \\
Unob. het. & No & Yes & Yes & Yes & Yes \\
\# parameters & 7 & 35 & 70 & 70 & 105 \\
LL & -5519 & -3784 & -3743 & -3703 & -3684 \\
AIC & 11,052 & 7638 & 7626 & 7546 & 7578 \\
BIC & 11,078 & 7767 & 7884 & 7804 & 7964 \\
McFadden $R^{2}$ & 0.164 & 0.427 & 0.433 & 0.439 & 0.442 \\
$\% 1 C H$ & 22.35 & 47.95 & 47.95 & 54.27 & 54.44 \\
\hline
\end{tabular}

parameters are estimated, as well as $35=(7 \times 5)$ effects of respondent-specific variables, that is, sociodemographic variables resp. personality variables, and 28 covariance parameters. In total, this leads to the estimation of $7+35+28=70$ parameters for the MXL1 and MXL2 models, respectively. The MXL+ model incorporates both unobserved heterogeneity and observed heterogeneity through sociodemographic variables and personality. Here, seven average part-worth utility parameters are estimated, as well as $70=2 \times 35=2 \times(7 \times 5)$ effects of respondent-specific variables, that is, sociodemographic and personality variables, and 28 covariance parameters. In total, this leads to the estimation of $7+70+28=105$ parameters. Table 3 compares the models' consideration of observed and unobserved heterogeneity, the number of parameters, fit statistics, e.g., log-likelihood values, AIC and BIC statistics and McFadden $\mathrm{R}^{2}$, and predictive validity, e.g., first choice hit rate $(\% 1 \mathrm{CH}){ }^{3}$

Obviously, the MNL model that does not account for any form of heterogeneity performs worst in terms of model fit and predictive validity. The McFadden $\mathrm{R}^{2}$ is also lower than the threshold of 0.2, which would indicate a good model fit (McFadden 1977). The consideration of unobserved heterogeneity (by the estimation of the individual level MXL model) contributes to a boost in the fit of the MXL0 model compared to that of the MNL model. In addition, the predictive validity, measured by the hit rate, doubles. Further accommodating for observed heterogeneity by sociodemographic variables in the MXL1 model slightly increases the model fit, measured by the log likelihood value, AIC and McFadden $\mathrm{R}^{2}$. However, its dominance in contrast to the MXL0 model is not thoroughly convincing because no improvements in predictive validity become obvious. Interestingly, the MXL1 model, which incorporates sociodemographic variables as observed variables, yields the same predictive validity as the MXL0 model, which accommodates no observed heterogeneity. Hence, sociodemographic variables alone seem to be insufficient to explain

\footnotetext{
3 The McFadden $\mathrm{R}^{2}$ compares the log-likelihood of the null model (LLO) with the log-likelihood of the estimated MNL resp. MXL model and is computed via $1-\left(\frac{L L}{L L 0}\right)$ (McFadden 1974). Here, the null model has a $\log$-likelihood value of $293 \times 14 \times \log \left(\frac{1}{5}\right)=-6601.9$.
} 
Table 4 Population means and selected parameter estimates by sociodemographic subgroups

\begin{tabular}{lcccccc}
\hline Parameters & \multicolumn{1}{l}{} & $\bar{\gamma}_{\text {female }}$ & $\bar{\gamma}_{\text {age }}$ & $\bar{\gamma}_{\text {acad.degree }}$ & $\bar{\gamma}_{>2600 €}$ & $\bar{\gamma}_{>4-\text { person-hh }}$ \\
\hline G-Star & $-1.433^{* * *}$ & $0.687^{* * *}$ & $-0.046^{* * *}$ & 0.619 & 0.153 & -0.252 \\
Levi's & $0.512^{* * *}$ & $0.435^{* *}$ & 0.002 & $0.681^{* * * *}$ & 0.012 & -0.081 \\
Replay & $-1.336^{* * *}$ & $0.669^{* * *}$ & $-0.027^{* * *}$ & $-0.492^{*}$ & $0.469^{* *}$ & $-0.634 * * *$ \\
Price & $-0.653^{* * *}$ & $-0.190^{* * *}$ & $-0.010^{* * *}$ & $-0.287^{* * *}$ & 0.001 & 0.002 \\
Trendy & 0.016 & 0.012 & $-0.010^{* * *}$ & $-0.163^{*}$ & -0.089 & 0.012 \\
FT label & $0.599^{* * *}$ & $0.160^{* *}$ & 0.004 & $0.256^{* * *}$ & $0.447 * * *$ & -0.059 \\
None & $0.898^{* * *}$ & $0.931^{* * *}$ & 0.000 & $0.429^{*}$ & $-0.421 * *$ & $-0.601 * * *$ \\
\hline
\end{tabular}

Parameters are significant at $p \leq 0.1(*), p \leq 0.05(* *), p \leq 0.01(* * *)$

preference heterogeneity in our sample. The MXL2 model that includes personality as an observed variable exceeds the MXL0 and MXL1 model both in terms of model fit, measured by the log-likelihood value, AIC and McFadden $\mathrm{R}^{2}$, and predictive validity. The predictive validity improves by approximately 6.32 percentage points when personality variables are incorporated to accommodate observed heterogeneity, which argues for personality variables' potential to explain preference heterogeneity.

However, the MXL+ model, which considers both the sociodemographic and personality variables of the respondents to explain consumer preferences, performs the best in term of fit, measured by the log likelihood value. The value of the AIC statistic is only slightly inferior to the AIC value of the MXL2 model. However, the MXL+ model yields the best predictive validity, which commonly constitutes the most dominant criterion for model selection in practical applications.

Not unexpectedly, the BIC statistic is best for the more parsimonious MXL0 model because the BIC statistic more strongly penalizes the number of estimated parameters. However, the BIC statistic is often criticized for underfitting, e.g., selecting models that are too simple (Burnham and Anderson 2002, p. 33). The likelihood ratio test between the MXL+ and MXL0 models yields a statistic of approximately 200, which is $\chi^{2}(70)$ distributed and indicates a highly significantly better model fit compared with the MXL+ model $(\mathrm{p}<0.001)$. Similarly, the model fit of the MXL+model is also significantly better compared to the MXL1 model. Here, the test statistic is approximately 117 and $\chi^{2}(35)$ distributed, and a $p$-value of less than 0.001 is observed. However, the likelihood-ratio test between the MXL2 and MXL+models is no longer significant $(p=0.318)$. This, as well as the results discussed before, argues for the potential of personality variables to explain more of the variance in heterogeneity compared to sociodemographic variables. However, the best-performing model is the MXL+model, which includes both types of observed variables.

We focus on the estimation results obtained from the MXL+ model because this model both performs best with respect to predictive validity and simultaneously enables the investigation of both types of observed variables, that is, personality and sociodemographics. Table 4 includes the utility parameter average values of the population distribution $\bar{\gamma}$ and the effects of the (mean-centered) respondent-specific 
Table 5 Selected parameter estimates by psychographic subgroups

\begin{tabular}{lcclll}
\hline Parameters & $\bar{\gamma}_{O}$ & $\bar{\gamma}_{E}$ & $\bar{\gamma}_{C}$ & $\bar{\gamma}_{N}$ & $\bar{\gamma}_{A}$ \\
\hline G-Star & 0.011 & 0.014 & -0.007 & $-0.045^{* *}$ & -0.010 \\
Levi's & $0.049^{* * *}$ & 0.006 & -0.028 & $-0.032^{*}$ & $-0.031^{*}$ \\
Replay & 0.011 & 0.025 & 0.021 & -0.030 & -0.022 \\
Price & $0.010^{* * *}$ & 0.000 & $0.017^{* * *}$ & -0.000 & $-0.013^{* * *}$ \\
Trendy & $-0.034^{* * *}$ & 0.003 & $0.046^{* * *}$ & -0.005 & $0.014^{*}$ \\
FT label & $0.015^{* * *}$ & $0.010^{*}$ & -0.009 & $0.013^{*}$ & $0.014^{*}$ \\
None & $-0.006^{* * *}$ & -0.008 & $-0.057^{* * *}$ & $0.064^{* * *}$ & $0.055^{* *}$ \\
\hline
\end{tabular}

Parameters are significant at $p \leq 0.1(*), p \leq 0.05(* *), p \leq 0.01(* * *)$

Table 6 Correlations of coefficients and standard deviations

\begin{tabular}{lrrrrrrr}
\hline & G-Star & \multicolumn{1}{c}{ Levi's } & Replay & Price & Trendy & FT label & None \\
\hline G-Star & 2.446 & & & & & & \\
Levi's & 0.104 & 2.168 & & & & & \\
Replay & 0.890 & 0.138 & 2.125 & & & & \\
Price & 0.427 & 0.248 & 0.340 & 0.778 & & & \\
Trendy & -0.330 & -0.209 & -0.102 & 0.054 & 0.561 & & \\
FT label & 0.204 & 0.048 & 0.344 & 0.032 & -0.239 & 1.376 & \\
None & -0.040 & 0.288 & 0.053 & -0.477 & 0.101 & 0.141 & 3.826 \\
\hline
\end{tabular}

sociodemographic variables on the average utility parameters of the population subgroups. The prices are scaled in $10 €$-units, which should be considered for the interpretation of the results with respect to, for example, the calculation of consumers' willingness-to-pay. ${ }^{4}$ We hereby consider a significance level of $90 \%$. As discussed before, due to potential attenuation bias in the estimated effects of the personality traits on preferences, we explicitly choose this slightly lower significant level in comparison to the often-used 95\% significant level. However, even $90 \%$ is commonly considered and still provides a strong influence of effects (Amrhein et al. 2019).

Table 5 illustrates the effects of the (mean-centered) respondent-specific personality variables on the average utility parameters by population subgroups.

Table 6 displays the correlations of the estimated parameters and the standard deviations as diagonal elements.

As listed in Table 4, the linear price parameter has an expected negative sign, which corresponds to the negative influences of increasing jeans prices. This result is plausible since jeans are nonluxury goods, and price does not necessarily signal quality. However, as displayed by the standard deviation of the price parameter (see

\footnotetext{
${ }^{4}$ For a detailed explanation of the calculation of a consumer's willingness-to-pay of the FT label from preference parameters, please refer to Paetz and Guhl (2017).
} 
diagonal element in Table 6), we can determine that there is some unobserved heterogeneity. Some respondents actually yield a positive price parameter and, therefore, do not regard price in its function of opportunity cost. While the brand "Levi's" is more preferred than the reference brand "Diesel", the brands "G-Star" and "Replay" are less preferred than "Diesel" on average. In general, the inclusion of an FT label increases consumers' preference, while the design level does not have any significant influence. However, we obtain a large amount of unobserved heterogeneity. For example, as displayed in Table 6, the standard deviation of the FT label parameter is quite large, suggesting that some people do not have any or even have a negative preference for the FT label, while other people exhibit a very high preference for this social product attribute. The price and FT label parameter are uncorrelated. Furthermore, we can observe positive correlations between the FT label and the brands "Replay" and "G-Star", while there is no correlation between the FT label and the brand "Levi's". Hence, customers of Levi's jeans seem to be brand-loyal and buy Levi's jeans independent of the inclusion of an FT label. Otherwise, the brands "Replay" and "G-Star" could actually gain from the inclusion of an FT label. This parallelism between the brands "Replay" and "G-Star" is further maintained by their great positive correlation, which contrasts the minor correlations with the brand "Levi's".

Based on the results shown in Tables 4 and 5, several interaction effects with respondent-specific variables become obvious as follows: the preference for the brand "Replay" increases if the consumer is female, younger and has no academic degree. Price sensitivity increases in females and consumers with an increasing age or academic degrees. Personality traits also correspond to price sensitivity. Consumers who are less open and less conscious or more agreeable show a higher price sensitivity than their corresponding counterparts. Regarding the focal research attribute "FT label", as revealed in Tables 4 and 5, the preference for the FT label is increased among females, consumers with an academic degree and consumers with a higher monthly (household) income. In addition, consumers' personality traits act as important drivers of the preference for social product attributes as follows: consumers who are more open, extraverted, neurotic and agreeable prefer the inclusion of an FT label.

The results of the sociodemographic drivers correspond to the results reported in the recent literature, which describes "the" social consumer as highly educated, wealthy and female (e.g., De Pelsmacker et al. 2005). The personality variables provide deeper insight into the characterization of social consumers and verify four of our hypothesis, namely, H1, H2, H3 and H5, which we derived in Sect. 2.3.

Our results mirror the results suggesting that the psychological consumer characteristic category "personal values" is a driver of social product preferences because we inter alia found agreeableness and openness to be positively related to social product preferences. These two personality traits are known to be strongly associated with personal values (Fischer and Boer 2015), which, in turn, were found to be moderators of social product preferences. This finding further maintains the plausibility of our results.

Furthermore, all of these results argue once more for the plausibility of selecting the MXL+model. The MXL+model seems to deliver unbiased results for the 
Table 7 Personality trait values of differing personality types

\begin{tabular}{llllll}
\hline & Openness & Extraversion & Consciousness & Neuroticism & Agreeableness \\
\hline Type 1 $(-\mathrm{O},-\mathrm{E},+\mathrm{N})$ & 2.193 & 0.213 & 10.038 & -0.059 & 10.860 \\
Type 2 $(+\mathrm{O},+\mathrm{E},-\mathrm{N})$ & 9.159 & 6.791 & 10.038 & -5.157 & 10.860 \\
Type 3 $(+\mathrm{A})$ & 5.676 & 3.502 & 10.038 & -2.608 & 13.820 \\
Type 4 $(-\mathrm{A})$ & 5.676 & 3.502 & 10.038 & -2.608 & 7.900 \\
\hline
\end{tabular}

effects of the personality variables: as displayed in Table 2, a moderate degree of correlation exists between certain sociodemographic variables and certain personality variables. Because, for example, both the openness (Table 5) and female (Table 4) variable positively affect the FT label utility and are positively correlated (Table 2), we could expect that the effect of openness is overstated in a model without sociodemographics, that is, the MXL2 model.

\subsection{Managerial implications}

Thus far, we discovered the driving potential of personality traits for customers' social product preferences. However, the question of how marketing managers could use this information to derive successful marketing strategies in the context of social consumption emerges. The following small simulation study should provide further insight into this topic.

We used a data set of German respondents, and therefore, we focus on the personality structures in Germany in our further research. In particular, we consider the personality differences between southern Germans and northern Germans and between western Germans and eastern Germans to derive geographic-specific marketing strategies, i.e., geographical market segmentation. Obschonka et al. (2018) created a psychological map of Germany. These authors used the five factor model to determine the respondents' personality and checked common "prejudices in the relation to the inhabitants of individual region of Germany" (Obschonka et al. 2018, p. 1), e.g., agreeable southern Germans or introverted east Germans. The authors revealed that east Germans are less open, more neurotic and less extraverted than western Germans. In contrast to northern Germans, southern Germans were more agreeable. Interestingly, the authors did not highlight regional, e.g., south-north or east-west, differences in the personality trait "consciousness".

Based on these results in the literature, we focus on four personality types, e.g., east Germans (type 1), western Germans (type 2), southern Germans (type 3) and northern Germans (type 4), to derive managerial marketing implications in the context of geographic market segmentation. To create these personality types, we rely on the mean values of our samples' personality factors and add resp. subtract half of the standard deviations of the relevant personality traits to determine the personality types. Table 7 shows the resulting personality factor values.

All personality traits that are not varied for a specific personality type are set to the sample's average values. Compared to the sample's mean-respondent, 
Table 8 Choice shares of jeans (overall and per personality type) [in \%]

\begin{tabular}{lrrrl}
\hline & Levi's & G-Star & Replay & Outside good \\
\hline Initial & & & & \\
Overall & 26.03 & 15.65 & 31.73 & 26.59 \\
Type 1 & 22.08 & 15.50 & 31.74 & 30.68 \\
Type 2 & 29.95 & 15.82 & 31.70 & 22.53 \\
Type 3 & 23.45 & 15.60 & 31.74 & 29.21 \\
Type 4 & 28.64 & 15.69 & 31.73 & 23.94 \\
G-Star with FT label & & & \\
Overall & 24.39 & 25.14 & 29.87 & 20.60 \\
Type 1 & 21.00 & 24.27 & 30.23 & 24.50 \\
Type 2 & 27.70 & 26.02 & 29.47 & 16.81 \\
Type 3 & 22.02 & 25.52 & 29.77 & 22.69 \\
Type 4 & 26.85 & 24.74 & 29.99 & 18.42 \\
\hline
\end{tabular}

personality type 2 (western Germans) is more open, more extraverted and less neurotic, while type 4 (northern Germans) is less agreeable. Following our purpose to ostensibly highlight the personality characteristics of social consumers, we do not consider sociodemographic differences between those different personality types.

For our simulation study, we assume an initial market that consists of an outside good and three products chosen in accordance with topical prices and modifications on a famous German online retailer for clothes as follows:

- Levi's/traditional design/100€/no FT label

- G-Star/trendy design/99€/no FT label

- Replay/trendy design/85€/no FT label

We calculate personality type-specific preferences based on the results of the MXL+model and use the logit model's share-of-choice rule. To stay consistent with the estimation, we also considered unobserved heterogeneity. Therefore, we integrate over the heterogeneity distribution. We already observed that the choice probabilities of the MXL model do not have a closed-form, and thus, the integral also does not have a closed-form. Hence, we must employ a numerical approximation to evaluate the integral (Dong and Koppelman 2014, p. 45). We used a Monte Carlo simulation and considered 100,000 draws to render the simulation error negligible. ${ }^{5}$

For the purpose of simplicity, we consider the same market volume of all four German regions, i.e., of all personality-type specific segments.

In the initial market, none of the products includes an FT label. The second line in Table 8 shows the resulting overall choice shares in this initial scenario. While the Replay jeans have the highest choice share, the G-Star's jeans have

\footnotetext{
5 For a detailed explanation of the numerical approximation in the context of the MXL model, please compare Dong and Koppelman (2014), pp. 45-46 or Elshiewy et al. (2017), pp. 41-42.
} 
Table 9 Sum of the absolute deviation between personality type-specific choice shares by market scenario [in percentage points]

\begin{tabular}{lrrrr}
\hline & Type 1 & Type 2 & Type 3 & Type 4 \\
\hline Type 1 & & 16.38 & 2.93 & 13.50 \\
Type 2 & 16.90 & & 13.45 & 2.88 \\
Type 3 & 4.55 & 12.35 & & 10.57 \\
Type 4 & 12.64 & 4.26 & 10.10 & \\
\hline
\end{tabular}

a choice share that is approximately half that of the Replay jeans. The Replay jeans have a dominant choice share that could be traced to its (currently) lowprice strategy. The market share of the outside good is $26.59 \%$.

We assume that the marketing manager of G-Star attempts to gain a competitive advantage by enhancing its jeans with an FT label. This strategy is not farfetched as Graf and Wirl (2014) determined that increasing completion drives companies to engage in corporate social responsibility activities. The modified jeans of G-Star with the FT label replace G-Star's jeans in the initial market scenario. As illustrated in Table 8, the jeans of G-Star could gain choice shares from both its direct competitors as well as from the outside good. Actually, the choice share of the outside good decreased to $20.60 \%$. Hence, G-Star's introduction of FT label jeans increased the market volume. Consumers now entered the jeans market explicitly due to the introduction of FT jeans.

Overall, G-Star's jeans have now outpaced Levi's jeans and yield a market share that is only 4.73 percentage points lower than the market share of the market leader, Replay. Overall, the competitive brands lose market shares of 1.64 (Levi's) and 1.86 (Replay) percentage points.

The enhancement of the G-Star's jeans with an FT label varies in its effects across the personality types. While G-Star's jeans gain less than the overall gain of 9.49 percentage points in the personality type segments 1 and 4, personality type segments 2 and 3 yield increases in the choice shares of 10.20 and 9.92 percentage points, respectively. Hence, ceteris paribus, type 2 and type 3 are more sensitive to the enhancement than their corresponding counterparts. However, G-Star's jeans modification is the most successful in western Germany (type 2), where the inhabitants are more open and more extraverted.

To gain further insight, we calculated the sum of absolute deviations in the personality type-specific choice shares for the initial market and the new market scenarios in a pairwise manner. The results are illustrated in Table 9. The upper triangle corresponds to personality type-specific differences in the initial market scenario, and the lower triangle yields the results for the new market scenario.

As illustrated in Table 9, the differences between type 1 and type 3, as well as between type 2 and type 4, are the lowest in both the initial and the new market scenarios. This finding supports the argument that the combination of the personality traits of (less/high) extraversion, (less/high) openness, and (high/low) neuroticism and the sole personality trait of (high/less) agreeableness lead to identical preference directions. This effect is further maintained by the parameter 
estimates shown in Table 4 that yield almost identical interaction effects between personality traits and social preferences for all significant personality traits, e.g., all interactions effects lie within a range of 0.005 .

Thus, we confirm our assumption (compare Sect. 2.3) that even different personality types may yield the same total preference for social product enhancements, and we show that this is quite important for the derivation of marketing strategies.

\section{Conclusions and future research}

Currently, social consumption constitutes a rapidly increasing trend with great potential for companies. Therefore, the characterization of social consumers is highly relevant for marketing practitioners and marketing academics. To date, sociodemographic variables have been widely used in marketing research to describe social consumers, but there have been recent calls for the characterization of social consumers using psychological variables, e.g., consumer's personality.

To contribute to the sparse literature related to this topic, we conduct an empirical study and investigate consumer personality as a psychological driver of consumers' preference for the FT label attribute (as a surrogate for social consumption). To operationalize consumer personality, we used the popular five-factor approach.

Based on data obtained using a discrete choice experiment in the product category of denim jeans, we estimated four types of mixed logit models that vary in their accommodation of observed heterogeneity, e.g., personality and sociodemographic variables. The new mixed logit model that incorporated both personality and sociodemographic variables dominated in terms of both fit and predictive validity. We find that gender, holding an academic degree, income and the four personality traits, e.g., extraversion, neuroticism, agreeableness and openness, are important drivers of consumers' social preferences. We determined the interaction effects between sociodemographic and personality variables and argue for the consideration of personality in the characterization of social consumers as the core source of social preferences.

Subsequently, we conduct a small simulation study to derive managerial implications for marketing managers and found regional differences in the success of social product enhancements in Germany. These differences were based on regional personality differences. Western Germans that are characterized as open, extraverted and less neurotic and southern Germans that are characterized as agreeable were found to be very sensitive to the introduction of FT jeans and responded with highly increased choice probabilities. Furthermore, the introduction of FT jeans to an already established market results in an increase in the overall market volume. Hence, jeans brands may actually benefit from the introduction of FT jeans by both drawing market shares from competitors as well as attracting completely new market customers.

In addition, the simulation study illustrates that personality traits should not be separately considered because each human exhibits all five personality traits simultaneously. Marketing managers should keep in mind that even different personality types may yield the same total preference for social product enhancements. This 
leads to a more differentiated view when -for example- product portfolio decisions have to be made. Hence, the introduction of new FT jeans or FT-enhanced product lines should be critically evaluated for specific regional markets that vary in their personality structure on first glance, but potentially yield the same total preference for the FT label attribute.

The relevance of our results for the derivation of marketing strategies is obvious, and future research may use our results in various research fields. The identification of the personality characteristics of "social consumers" is crucial for marketing academics and practitioners. Specifically, marketing managers could use the information of highly extraverted, neurotic, agreeable and open social consumers for managerial implications. For example, managers could use these results to create an appropriate (brand) personality for their social brands. Following congruency theory, consumers tend to prefer brands that conform to their personality traits. Marketing managers may rely on the positive relationships between the personality traits of social consumers and brand personality (traits). For example, based on the brand personality scale proposed by Aaker (1997), several studies found positive relationships between the consumer personality traits agreeableness and openness and the two brand personality traits sincerity and excitement. Hence, we may conclude that social brands should highlight (one of) these brand personality traits to attract social consumers.

In addition, marketing managers could use the precise personality characterization of social consumers to derive operative marketing strategies. For example, managers could make decisions regarding advertising (campaigns) for products that incorporate social product attributes. One prominent example of advertising that highlights social consumerism is the actual advertising campaign of the coffee brand "Nespresso". In the advertisements, the protagonist is a coffee farmer's daughter who is able to attend a university because her father is fairly compensated (Nespresso 2018).

Since this paper is among the first to characterize social consumers based on their personality traits, there is a need for future research.

In this paper, we considered only one (German) data set. Because the five-factor approach of personality is appropriate for all cultures, it could be interesting to replicate the present study using data sets from different cultures. In addition, we considered denim jeans the focal research objective. As previously explained, denim jeans are fashion products, and the recent literature has already reported that choices between denim jeans are known to be more emotionally driven than choices between nondurable goods, such as food or flowers (cp. Watson and Yan 2013). In more emotionally driven choices, personality traits are generally known to have a strong influence on consumer behavior (Roccas et al. 2002). Hence, the replication of our study in further product categories with choice decisions that are less intuitive or emotionally driven could provide further insight into the appropriateness of the personality characterization of social consumers. 
Acknowledgements Open Access funding provided by Projekt DEAL.

Open Access This article is licensed under a Creative Commons Attribution 4.0 International License, which permits use, sharing, adaptation, distribution and reproduction in any medium or format, as long as you give appropriate credit to the original author(s) and the source, provide a link to the Creative Commons licence, and indicate if changes were made. The images or other third party material in this article are included in the article's Creative Commons licence, unless indicated otherwise in a credit line to the material. If material is not included in the article's Creative Commons licence and your intended use is not permitted by statutory regulation or exceeds the permitted use, you will need to obtain permission directly from the copyright holder. To view a copy of this licence, visit http://creativecommons.org/licen ses/by/4.0/.

\section{References}

Aaker JL (1997) Dimensions of brand personality. J Mark Res 34:335-347

Aaker D (2008) Strategic market management, 7th edn. Wiley India Pvt. Limited, Chichester

Abou-Zeid M, Ben-Akiva M (2014) Hybrid choice models. In: Hess S, Daly A (eds) Handbook of choice modelling. Edward Elgar Publishing, Cheltenham, pp 383-412

Allenby G, Ginter JL (1995) Using extremes to design products and segment markets. J Mark Res 32:392-403

Amrhein V, Greenland S, Mcshane B (2019) Retire statistical significance. Comment. Nature 567:305-307

Anderson WT, Cunningham WH (1972) The socially conscious consumer. J Mark 36:23-31

Andorfer VA, Liebe U (2012) Research on fair trade consumption-a review. J Bus Ethics 106:415-435

Asendorpf JB (2004) Psychologie der Persönlichkeit [Psychology of personality], 3rd edn. Springer, Berlin

Auger P, Devinney TM, Louviere JJ, Burke PF (2010) The importance of social product attributes in consumer purchasing decisions: a multi-country comparative study. Int Bus Rev 19:140-159

Balderjahn I, Hüttel A (2019) Why consumers buy sustainably: the role of personal values. Marketing ZFP. J Res Manag 41:24-38

Bhat CR, Gossen R (2004) A mixed multinomial logit model analysis of weekend recreational episode type choice. Transp Res Part B: Methodol 38:767-787

Burnham K, Anderson D (2002) Model selection and multimodel inference: a practical information-theoretic approach, 2nd edn. Springer, New York

Carrigan M, Szmigin I, Wright J (2004) Shopping for a better world? An interpretive study of the potential for ethical consumption within the older market. J Consumer Mark 21:401-441

Clark L, Calli L (2014) Personality types and Facebook advertising: an explorative study. J Direct Data Digit Mark Pract 15:327-336

Costa PT, McCrae RR (1992) Revised NEO personality inventory (NEO-PI-R) and neo five-factor inventory (NEO-FFI) professional manual. Psychological Assessment Resources, Odessa

Costa PT, McCrae RR (2003) Personality in adulthood: a five-factor theory perspective, 2nd edn. Routledge, New York

Costa PT, Terracciano A, McCrae RR (2001) Gender differences in personality traits across cultures: robust and surprising findings. J Pers Soc Psychol 81:322-331

Cranfield J, Henson S, Northey J, Masakure O (2010) An assessment of consumer preference for fair trade coffee in Toronto and Vancouver. Agribusiness 26:307-325

Cranford RE, Smith DR (1987) Consciousness: the most critical moral (constitutional) standard for human personhood. Am J Law Med 13:233-248

Croissant Y (2020) Estimation of multinomial logit model in R: the Package mlogit. R package version 0.2-4. https://CRAN.R-project.org/package=mlogit. Accessed 16 Mar 2020

De Pelsmacker P, Driessen L, Rayp G (2005) Do consumers care about ethics? Willingness to pay for fair-trade coffee. J Consumer Aff 39:363-385

De Raad B (2000) The big five personality factors: a psycholexical approach to personalit. Hogrefe, Göttingen 
Devinney, TM, Auger P, Eckhardt G, Birtchnell T (2006) The other CSR. Stanford Social Innovation Review. https://papers.ssrn.com/sol3/papers.cfm?abstract_id=901863. Accessed 19 Dec 2019

Dickson MA (2000) Personal values, beliefs, knowledge, and attitudes relating to intentions to purchase apparel from socially responsible businesses. Cloth Text Res J 18:19-30

Diener C, Orme B, Yardley D (2006) Dual response "none" approaches: theory and practice. In: Sawtooth Software Inc. (ed) Proceedings of the Sawtooth Software Conference 2006, pp 157-168. https:// www.sawtoothsoftware.com/download/techpap/2006Proceedings.pdf. Accessed 18 Dec 2019

Digman JM (1990) Personality structure: emergence of the five-factor model. Annu Rev Psychol 41:417-440

Divine RL, Lepisto L (2005) Analysis of the healthy lifestyle consumer. J Consumer Mark 22:275-283

Dong X, Koppelman F (2014) Comparison of continuous and discrete representations of unobserved heterogeneity in logit models. J Mark Anal 2:43-58

Elshiewy O, Guhl D, Boztug Y (2017) Multinomial logit models in marketing-from fundamentals to state of the art. Marketing ZFP. J Res Manag 39:32-49

FairTrade (2018) Aims of fair trade standards. https://www.fairtrade.net/standards/aims-of-fairtrade-stand ards.html\#c3782. Accessed 17 Dec 2019

Fan Y (2005) Ethical branding and corporate reputation. Corp Commun: Int J 10:341-350

Fischer R, Boer D (2015) Motivational basis of personality traits: a meta-analysis of value-personality correlations. J Pers 83:491-510

Fritzsche DJ (1995) Personal values: potential keys to ethical decision making. J Bus Ethic 14:909-922

Glöckner A, Balderjahn I, Peyer M (2010) Die LOHAS im Kontext der Sinus-Milieus [LOHAS in context of sinus milieus]. Mark Rev St. Gallen 27:36-41

Goldberg LR (1990) An alternative description of personality: the big-five factor structure. J Pers Soc Psychol 59(6):1216-1229

Goldberg LR (1992) The development of markers for the big-five factor structure. Psychol Assess 4:26-42

Gosling SD, Rentfrow PJ, Swann WB (2003) A very brief measure of the big five personality domains. J Res Psychol 37:504-528

Graf C, Wirl F (2014) Corporate social responsibility: a strategic and profitable response to entry? J Bus Econ 84:917-927

Grankvist G, Kajonius P (2015) Personality traits and personal values: a replication with a swedish sample. Int J Pers Psychol 1:8-14

Greene WH, Hensher DA, Rose J (2006) Accounting for heterogeneity in the variance of unobserved effects in mixed logit models. Transp Res Part B: Methodol 40:75-92

Günther A, Höfler M (2006) Different results on tetrachorical correlations in mplus and stata-stata announces modified procedure. Int J Methods Psychiatr Res 15:157-166

Haase FV, Kohlmeyer M, Rich B, Woll R (2016) Determination of additional willingness to pay for socially responsible technical products using discrete choice analysis. J Manag Sustain Can Center Sci Educ 6:45-58

Hainmueller J, Hiscox MJ, Sequeira S (2015) Consumer demand for fair trade: evidence from a multistore field experiment. Rev Econ Stat 97:242-256

Harris MA, Brett CE, Johnson W, Deary IJ (2016) Personality stability from age 14 to age 77 years. Psychol Aging 31:862-874

Helmke S, Scherberich JU, Uebel M (2016) LOHAS marketing. Springer, Wiesbaden

Hogan R (1986) Hogan personality inventory. National Computer Systems, Minneapolis

Huber J, Zwerina K (1996) The importance of utility balance in efficient choice designs. J Mark Res 33:307-317

Inglehart R, Beker WE (2000) Modernization, cultural change, and the persistence of traditional values. Am Sociol Rev 65:19-51

Jeansdirect (2018) Die Jeans in Zahlen [Quantify jeans] https://www.jeans-direct.de/blog/article/die-jeans -in-zahlen. Accessed 15 Mar 2020

Jin B, Park JY, Ryu JS (2010) Comparison of chinese and indian consumers' evaluative criteria when selecting denim jeans: a conjoint analysis. J Fashion Mark Manag 14:180-194

Kahle LR (1983) Social values and social change: adaptation to life in America. Praeger, New York

Kahle LR, Beatty SE, Homer P (1986) Alternative measurement approaches to consumer values: the list of values (LOV) and life styles (VALS). J Consumer Res 13:405-409

Kucukemiroglu O (1999) Market segmentation by using consumer lifestyle dimensions and Ethnocentrism. Eur J Mark 33:470-487 
Lazer W (1963) Lifestyle concepts and marketing. In: Greysser S (ed) Toward scientific marketing. American Marketing Association, Chicago, pp 243-252

Lee SH, Sparks B (2007) Cultural influences on travel lifestyle: a comparison of korean Australians and Koreans in Korea. Tour Manag 28:505-518

Matz S, Kosinski M, Nave G, Stillwell D (2017) Psychological targeting as an effective approach to digital mass persuasion. Proc Natl Acad Sci 114:12714-12719

McCrae RR, Costa PT (1982) Self-concept and the stability of personality: cross-sectional comparisons of self-reports and ratings. J Pers Soc Psychol 43:1282-1292

McCrae RR, Costa PT Jr (1987) Validation of the five-factor model of personality across instruments and observers. J Pers Soc Psychol 52:81-90

McCrae RR, Costa PT (1996) Towards a new generation of personality theories: theoretical contexts for the five factor model. In: Wiggins JS (ed) The five-factor model of personality. The Guilford Press, New York, pp 51-87

McCrae RR, Costa PT (2008) The five-factor theory of personality. In: John OP, Robins RW, Pervin LA (eds) Handbook of personality, 3rd edn. The Guilford Press, New York, pp 159-181

McCrae RR, Costa PT (2013) Introduction to the empirical and theoretical status of the five-factor model of personality traits. In: Widiger TA, Costa PT (eds) Personality disorders and the five-factor model of personality,3rd edn. American Psychological Association, Washington, pp 15-27

McCrae RR, John OP (1992) An introduction to the five-factor model and its applications. J Pers 60:175-215

McCrae RR, Costa PT, Ostendorf F et al (2000) Nature over nurture: temperament, personality, and life span development. J Pers Soc Psychol 78:173-186

McCrae RR, Terracciano A et al (2005) Universal features of personality traits from the observer's perspective: data from 50 cultures. J Pers Soc Psychol 88:547-561

McFadden DL (1974) Conditional logit analysis of qualitative choice behavior. In: Zarembka P (ed) Frontiers in econometrics. Academic Press, New York, pp 105-142

McFadden D (1977) Quantitative methods for analyzing travel behavior of individuals: some recent developments. Institute of Transportation Studies, University of California, Oakland

McFadden D, Train KE (2000) Mixed mnl models for discrete response. J Appl Econom 15:447-470

Nespresso (2018) Meet Humberto, Luis Miguel and Esteban: some of the real farmers behind Nespresso's extraordinary coffees. https://www.nestle-nespresso.com/newsandfeatures/Meet-Humberto-LuisM iguel-and-Esteban-some-of-the-real-farmers-begind-Nespressos-extraordinary-coffees. Accessed 16 Dec 2019

Newton P, Meyer D (2013) Exploring the attitudes-action gap in household resource consumption: does environmental lifestyle segmentation align with consumer behaviour? Sustainability 5:1211-1233

Obschonka W, Fritsch G, Rentfrow P (2018) The psychological map of Germany. https://www4.uni-jena. de/en/Research+News/FM180903_psychological+map+of+Germany.html. Accessed 16 Dec 2019

Paetz F (2016) Persönlichkeitsmerkmale als Segmentierungsvariablen: eine empirische Studie [Personality traits as segmentation basis: an empirical study]. Schmalenbachs Zeitschrift für betriebswirtschaftliche Forschung 68:279-306

Paetz F, Guhl D (2017) Understanding differences in segment-specific willingness-to-pay for the fair trade label. Marketing ZFP. J Res Manag 39:37-46

Paetz F, Guhl D (2018) How fairness-consciousness impacts consumer's willingness-to-pay for fair product attribute: Insights from an advanced estimation approach. https://ssrn.com/abstract=3193808. Accessed 16 Dec 2019

Parks-Leduc L, Feldman G, Bardi A (2015) Personality traits and personal values: a meta-analysis. Pers Soc Psychol Rev 19:3-29

Peloza J, White K, Shang J (2013) Good and guilt-free: the role of self-accountability in influencing preferences for products with ethical attributes. J Mark 77:104-119

Poelmans E, Rousseau S (2016) How do chocolate lovers balance taste and ethical considerations? $\mathrm{Br}$ Food J 118:343-361

Rao VR (2014) Applied conjoint analysis. Springer, New York

Rasouli S, Timmermans H (2016) Influence of social Networks on latent choice of electric cars: a mixed logit specification using experimental design data. Netw Spatial Econmics 16:99-130

Ray PH, Anderson SR (2000) The cultural creatives. How 50 Million people are changing the world. Three Rivers Press, New York

Renard MC (2003) Fair trade: quality, market and conventions. J Rural Stud 19:87-96 
Roccas S, Sagiv L, Schwartz SH, Knafo A (2002) The big five personality factors and personal values. Pers Soc Psychol Bull 28:789-801

Rokeach M (1973) The nature of human values. The Free Press, New York

Rousseau S (2015) The role of organic and fair trade labels when choosing chocolate. Food Qual Prefer 44:92-100

Rozgonjuk D, Ryan T, Kuljus J, Täht K, Scott G (2019). Social comparison orientation mediates the relationship between neuroticism and passive Facebook use. Cyberpsychol: J Psychosoc Res Cyberspace 13(1). Article 2

Saum-Aldehoff T (2012) Big Five: Sich selbst und andere erkennen [Recognize yourself and others], 2nd edn. Patmos, Ostfildern

Schön H (2007) Personality Traits and Foreign Policy attitudes in german public opinion. J Conflict Resolut 51:408-430

Schüpbach SS, Gröli M, Dauwalder P, Amhof R (2007) LOHAS lifestyle of health and sustainability. Ernst\&Young, Switzerland. https://www.lohas.se/wp-content/uploads/2015/07/ErnstYoung-Studi e-2008_ey_LOHAS_e.pdf. Accessed 14 Dec 2019

Schwartz SH (1992) Universals in the content and structure of values: theoretical advances and empirical tests in 20 countries. In: Zanna M (ed) Advances in experimental social psychology, vol 25. Academic Press, New York, pp 1-65

Specht J, Egloff B, Schmukle SC (2011) Stability and change of personality across the life course: the impact of age and major life events on mean-level and rank-order stability of the big five. J Pers Soc Psychol 101:862-882

Statista (2015) Ranking of the most popular fashion brands (based on clothing items owned) in Germany in 2015. https://www.statista.com/statistics/505238/clothing-most-popular-fashion-brands-germa ny/. Accessed 14 Dec 2019

Statista (2018a) Bevölkerung-Einwohnerzahl in Deutschland nach Geschlecht von 1995 bis 2018 [Population in Germany by gender from 1995 to 2018] https://de.statista.com/statistik/daten/studi e/161868/umfrage/entwicklung-der-gesamtbevoelkerung-nach-geschlecht-seit-1995/. Accessed 15 Mar 2020

Statista (2018b) Bildungsstand: Verteilung der Bevölkerung in Deutschland nach beruflichem Bildungsabschluss [Level of education: distribution of the german population according to vocational qualification]. https://de.statista.com/statistik/daten/studie/3276/umfrage/bevoelkerung-nach-beruf lichem-bildungsabschluss/. Accessed 15 Mar 2020

Statista (2018c) Anzahl der Haushalte in Deutschland nach Anzahl der Personen im Haushalt von 2000 bis 2018 [Number of German households based on the number of persons in household from 2000 to 2018]. https://de.statista.com/statistik/daten/studie/167169/umfrage/entwicklung-der-haushaltsg roessen-in-deutschland-seit-2000/. Accessed 15 Mar 2020

Statista (2018d) Verteilung der Privathaushalte in Deutschland nach monatlichem Haushaltsnettoeinkommen im Jahr 2018 [Distribution of German households by monthly netto household income in 2018]. https://de.statista.com/statistik/daten/studie/3048/umfrage/privathaushalte-nach-monatliche m-haushaltsnettoeinkommen/. Accessed 15 Mar 2020

Statista (2018e) Durchschnittsalter der Bevölkerung in Deutschland von 2011 bis 2018 [Mean age of German population from 2011 to 2018]. https://de.statista.com/statistik/daten/studie/1084430/umfrage/ durchschnittsalter-der-bevoelkerung-in-deutschland/. Accessed 15 Mar 2020

Statista (2019) Claims and certifications on food or beverage product packaging that have influence on purchasing behavior in the United States as of 2017. https://www.statista.com/statistics/809400/ food-package-claims-and-certifications-impact-on-purchasing-behavior/. Accessed 14 Dec 2019

Streiner DL (2003) Starting at the beginning: an introduction to coefficient alpha and internal consistency. J Pers Assess 80:99-103

Train K (2009) Discrete choice methods with simulation, 2nd edn. Cambridge University Press, Cambridge

Tully SM, Winer RS (2014) The role of the beneficiary in willingness to pay for socially responsible products: a meta-analysis. J Retail 90:255-274

Warburg V, Bhat C, Adler T (2006) Modeling demographic and unobserved heterogeneity in air passengers' sensitivity to service attributes in itinerary choice. Transp Res Rec 1951:7-16

Watson MZ, Yan RN (2013) An exploratory study of the decision processes of fast versus slow fashion consumers. J Fashion Mark Manag J 17:141-159

Wedel M, Kamakura WA (2000) Market segmentation—conceptual and methodological foundations, 2nd edn. Norwell, Kluwer 
Wells W, Tigert DJ (1977) Activities, interests, and opinions. J Advert Res 11:27-35

Wenzel E, Rauch C, Kirig A (2007) Zielgruppe LOHAS. Wie der grüne Lifestyle die Märkte erobert [Target group LOHAS: How the green lifestyle rules the market]. Zukunftsinstitut, Kelkheim

World Data (2019) Average income around the world https://www.worlddata.info/average-income.php. Accessed 14 Dec 2019

Publisher's Note Springer Nature remains neutral with regard to jurisdictional claims in published maps and institutional affiliations. 